refreshing to read of places whore attempts are being made to show how science can be taught to adults in the local community. The luncheon room of the Fox Inn in Worcestershire is such a place, and here, under the auspices of the Extra-Mural Department of the University of Birmingham, Gilbert Cope has recently completed a series of lectures on biological topics to a representative cross-section of the local male population (Further Education, 3, No. 2; September-November 1949). Since the lectures were held at the normal place of evening congregation little could be attempted in the way of demonstration, but the use of topical films added to the interest of the course. To arouse enthusiasm, this course had been preceded by a trial run of four lectures on soils and plant physiology which had been succeeded by another course on more practical aspects of farming like breeding and rearing, feeding, milking, calf rearing, and management of young stock. The real value of further education of this kind is that it brings the results of scientific research to the people who can effectively employ them. and so unites academic achievement with practical labour.

\section{Weekly Records of Earthquake Epicentres}

ThE epicentre cards sent out by the United States Coast and Geodetic Survey, Washington, D.C., and prepared by the Survey in co-operation with Science Service and the Jesuit Seismological Association, have long been a boon to seismological observatories. These observatories are now more deeply indebted to the Survey, under its director, Rear-Admiral L. O. Colbert, for a new series of weekly cards, the first of which was issued on June 30,1949 , giving a tabulation of minor earthquakes. The range of epicentres is world-wide, and for each earthquake the initial time is given together with the preliminary determination of epicentre (latitude and longitude) if observations warrant this-otherwise the epicentral area is named. The first earthquake mentioned occurred on June 12, and the weekly numbers listed have been $7,5,8,7$, $21,9,8,11,5,27,7$ and 7 so far. Although the new lists are probably not entirely comprehensive, chiefly owing to lack of a complete world-wide network of observatories and also difficulties of communication, they do give an idea of the seismic activity in the world when coupled with the details of major earthquakes on the epicentre cards (old series) which have been issued by the same office for so long.

\section{Blundell's School Science Society}

Two articles in the magazine of Blundell's School Science Society show the high standard of work which can be obtained from schoolboys who are encouraged to do original work. In one, O. F. Amor describes some observations made on the effect of acidity on the distribution of Gammarus pulex in a moorland stream. Although the investigations could not be conducted on a scale to justify firm conclusions, the evidence obtained indicates that $G$. pulex does not tolerate a $p \mathbf{H}$ lower than $\mathbf{6 \cdot 5}$. It is probable that this freshwater shrimp cannot exist long in water of this acidity, but that a neutral or slightly alkaline medium of $p \mathrm{H} 7-7 \cdot 5$ is favourable. In the other article, D. C. R. Stephens discusses the competition between weeds and grasses from investigations made in various school lawns. His observations confirm the theoretical requirements for a successful weed in a lawn, namely, rapid germination, growth and development, rapid reproduction and effective means of evading the mower. The magazine also contains an account of a study of the blue-tit as well as records made by the ornithological, meteorological and other sections.

\section{Frank B. Jewett Fellowships: New Awards}

The American Telephone and Telegraph Co. has awarded Frank B. Jewett fellowships to the following: Dr. J. B. French, a graduate in physies and mathematics of Dalhousie University, Nova Scotia, and the Massachusetts Institute of Technology, for research at the Institute for Advanced Study, Princeton, on higher-order radiative processes in the quantum theory of fields; Dr. Ilse L. Novak, a graduate in mathematics of Hunter College and Radeliffe College, for research at the University of California on relation algebras; Mr. R. F. Steiner, a graduate in chemistry of Princeton University and at present a graduate student at Harvard University, for research at the University of California on light scattering of the actin-myosin system, and its relation to the phenomena of muscular contraction ; Dr. D. E. Mann, a graduate in chemistry and physics of the City College of New York and the University of Chicago, for research in quantum mechanics at Harvard University (Dr. Mann held a Jewett fellowship last year); Dr. Roy J. Glauber, a graduate in physics of Harvard University and at present an Atomic Energy Commission postdoctorate fellow at the Institute for Advanced Study, Princeton, for research at the Institute on the theory of elementary particles. Grants for the fellowships were established in 1944 by the American Telephone and Telegraph Co. upon the retirement of the late Dr. Jewett as vice-president in charge of development and research, and since that time thirty-three awards have been made. The fellowships are designed to stimulate and assist research in the fundamental physical sciences by men of science who have recently received or are due to receive doctorates. The awards are made on the recommendation of a committee of seven from the Bell Telephone Laboratories ; they carry a grant of 3,000 dollars to the recipient and 1,500 dollars to the institution at which the research is done.

\section{Colonial Service : Recent Appointments}

The following appointments in the Colonial Service have been recently announced: E. Bellis (agricultural officer, Kenya), soil chemist, Kenya; C. W. S. Hartley (agricultural officer, Federation of Malaya), senior agricultural officer (research), Federation of Malaya; M. Greenwood (principal agricultural officer, Nigeria), assistant director of agriculture (experiments), Nigeria ; H. J. S. Simpson (agricultural officer, Federation of Malaya), senior agricultural officer, Federation of Malaya; O. J. Voelcker (director, West African Cocoa Research Institute, Gold Coast), director of agriculture, Federation of Malaya ; J. West (principal research officer, West African Cocoa Research Institute, Gold Coast), director, West African Cocoa Research Institute, Gold Coast ; L. G. T. Wigg (senior assistant conservator of forests, Tanganyika), deputy conservator of forests, Tanganyika; G. M. Stockley (chief geologist, Tanganyika), director of geological survey, Tanganyika; J. G. Black (veterinary surgeon, British Guiana), veterinary officer, Northern Rhodesia; D. Sheriff (veterinary officer, Northern Rhodesia), veterinary officer, Kenya; W. Uruski (veterinary officer, British Guiana), senior veterinary officer, 